\title{
¿A QUIÉNES CORRESPONDE LA DENOMINACIÓN DE MAGISTRADO EN EL PERÚ?
}

\author{
¿Who is called a Magistrate in Perú?
}

\section{Sidney Alex Bravo Melgar}

Doctor en Derecho y Ciencia Política Universidad Nacional Mayor de San Marcos (La más antigua de América). Magister en Derecho Civil y Comercial Universidad de San Martin de Porres. Abogado. Universidad Católica de Santa María Catedrático de Postgrado de la Universidad Andina del Cusco y de la Universidad Santiago Antúnez de Mayolo-Ancash. Ex Juez Superior de la Corte Superior de Lima N. Conferencista Nacional e Internacional.

E-mail: sidneybravo@hotmail.com

Convidado

RESUMO: El presente artículo, está encaminado al análisis del término magistrado, respecto a su concepto, elementos, alcances, facultades, entre otros. Asimismo, examinaremos exhaustivamente a quién corresponde adjudicar en sentido estricto la denominación de magistrado, ¿será a los integrantes de los órganos jurisdiccionales del Poder Judicial o a los representantes del Ministerio Público? O ¿quizás será a los representantes de otros entes públicos? Para dilucidar esta interrogante, recurriremos a legislación nacional y comparada, a su vez a concepciones doctrinarias diversas al respecto. Seguidamente efectuaremos un parangón, entre la legislación española, chilena, colombiana, mexicana, brasilera, venezolana, y la nuestra.

En pocos países del orbe, se denomina magistrado tanto al juez como al fiscal, el Perú es uno de ellos. En tal virtud, por las razones supra expuestas, consideramos que debemos solucionar esta disyuntiva, que ha generado mucha confusión. Por consiguiente, luego de plasmar todo lo relativo a nuestro epígrafe, propondremos la modificación de algunas normas, que devienen en incongruentes, inadecuadas e imprecisas. Ergo, es menester su modificación.

Palavras-chave: Magistrado, juez, fiscal, atribuciones, Poder Judicial, Ministerio Público, ley, país.

ABSTRACT: This article is aimed at the analysis of the term magistrate, regarding its concept, elements, scope, faculties, among others. Likewise, we will exhaustively examine who corresponds to strictly assign the name of magistrate, will it be to the members of the judicial bodies of the Judiciary or to the representatives of the Public Ministry? Or perhaps it will be the representatives of other public entities? To elucidate this question, we will resort to national and comparative legislation, in turn to diverse doctrinal conceptions in this regard. Then we will make a comparison among Spanish, Chilean, Colombian, Mexican, Brazilian, Venezuelan, and ours legislation.

In few countries in the world, both the judge and the prosecutor are called magistrates, Peru is one of them. By virtue of this, for the reasons stated above, we consider that we must resolve this dilemma, which has generated much confusion. Therefore, after translating everything related to our heading, we will propose the modification of some rules, which become inconsistent, inadequate and imprecise. Ergo, its modification is necessary. 
Keywords: Judge, prosecutor, attributions, Judicial Power, Public Ministry, law, country.

SUMÁRIO: Introducción. 1 Antecedentes históricos. 2 Concepto y alcances del término juez. 3 Concepto y alcances del vocablo fiscal. 4 ¿A quiénes corresponde denominar como magistrados en nuestro país? 4.1 ¿Se deben denominar magistrados a todos los que por ius imperium imparten justicia dentro del Poder Judicial? 4.2 ¿Es correcto denominar magistrados, a los representantes del Ministerio Público? 4.3 ¿Cabe denominar magistrados a los representantes de otros entes autónomos en nuestro País? 4.3.1 Jurado Nacional de Elecciones. 4.3.2 Junta Nacional de Justicia, 5.3.3. Tribunal Constitucional. 5 Jerarquización de los Jueces en otros países del orbe. 5.1 España, 5.2 En Chile. 5.3 En Colombia. 5.4 En México. 5.5 En Brasil. 5.6 En Venezuela. Conclusiones. Referencia.

\section{INTRODUCCIÓN}

En nuestro país tanto al juez como al fiscal de todos los niveles jerárquicos se les denomina magistrados. En principio, respecto a los fiscales, consideramos que es un error denominarlos magistrados, puesto que según nuestro criterio no lo son. Probablemente la justificación en la que se amparan, para emplear dicha denominación, radica en lo prescrito por el artículo 2 de la ley $\mathrm{N}^{\circ}$. 26335 (Ley Orgánica de la Academia de la Magistratura), cuyo tenor ad pedem litterae es el siguiente:

\section{Artículo 2. La Academia de la Magistratura tiene por objeto:}

a) La formación académica de los aspirantes a cargos de magistrado del Poder Judicial o del Ministerio Público.

b) La capacitación académica para los ascensos de los magistrados del Poder Judicial o del Ministerio Público.

c) La actualización y perfeccionamiento de los magistrados del Poder Judicial y del Ministerio Público.

Si efectuamos una interpretación literal, prima facie podemos advertir, que la norma traída a colación comprende indistintamente el término magistrados, tanto para jueces como para fiscales en general. Sin embargo, es menester interpretar teleológica y sistemáticamente la norma, a efectos de desentrañar el espíritu de la ley y colegir cuál es verdaderamente su contenido, ámbito de aplicación y alcances; al hacerlo, presumimos juris tantum que los legisladores se apresuraron y equivocaron en la redacción de la ley, que apenas comprende 14 artículos, más aún al plasmar el contenido del artículo 2, ya que lo correcto hubiese sido consignar los términos: "magistrados del Poder Judicial y representantes del Ministerio Público". La razón es simple, los Jueces si realizan funciones propias de un magistrado, que son la de juzgar y sentenciar, al hacerlo ponen fin a la presunción de inocencia consagrada en el artículo 2, inciso 24, literal e) de la Constitución Política del Perú, en cambio los fiscales, son representantes del Ministerio Público, que tienen la naturaleza de funcionarios públicos, son los titulares de la acción penal, se encargan de realizar actos administrativos que coadyuvan con la actividad jurisdiccional que es propia de los jueces, dichos actos se concretan mediante la investigación de los hechos imputables y la respectiva acusación al encausado, sin perjuicio de las demás facultades que tienen conforme a ley. Ergo, no es correcto denominar magistrados a los fiscales, porque no desempeñan los roles que le son inherentes a los jueces y a su vez no reúnen los requisitos sine que non de dicha labor. Cabe comentar que el Decreto Legislativo Nro. 052 que se configura como la Ley Orgánica del Ministerio Público, en ninguno de sus preceptos denomina magistrado a los fiscales en general. Sin embargo, el inciso 2 
de los artículos 6 y 7 de la Ley $N^{\circ} .30483$ (Ley de la Carrera Fiscal), al fijar los requisitos especiales para ser fiscal supremo y fiscal superior, contemplan el vocablo magistrado. Consideramos que, lo plasmado en las normas supra expuestas, no se consolidan como una fundamentación jurídico-legal erga omnes que nos permita libremente, adjudicar a los fiscales el epígrafe magistrados, puesto que in stricto sensu no lo son. En tal virtud, denominar a los jueces y fiscales como magistrados, es un yerro salvable. La paridad o equivalencia respecto a la nomenclatura aludida, no es correcta ni adecuada.

En lo concerniente al Poder Judicial, se advierte que en nuestro país a todos los jueces de todos los niveles y categorías se les denomina magistrados, a diferencia de otros países como España, Colombia, Chile, Brasil, Venezuela, entre otros. En consecuencia, es menester tratar estos temas, con la finalidad de dilucidar estas desavenencias.

También existen otros entes públicos como son el Jurado Nacional de Elecciones, la Junta Nacional de Justicia y el Tribunal Constitucional, a cuyos miembros se les denomina magistrados. Analizaremos si es correcto o no in stricto sensu, la utilización de este epígrafe para referirse a ellos.

\section{ANTECEDENTES HISTÓRICOS}

La presencia y funciones del juez, obedecen a la edad antigua, puesto que ya existieron en la cultura egipcia, persa, china, romana, griega entre otras. Se adoptaron diversas nomenclaturas para referirse al juez; así tenemos que, en la antigua Roma, se denominaba pretor urbano al que impartía justicia entre los ciudadanos y pretor peregrino, al que resolvía los conflictos entre ciudadanos romanos y bárbaros (extranjeros).

El código de Hammurabi que emanó en el año 1762 a.C. creó tribunales de justicia conformado por jueces probos, a tal punto que una de sus regulaciones prescribía que, si el juez variaba su sentencia, debía abonar una multa 12 veces mayor al monto en discusión.

En la India el código de Manu, que data 200 a.C. fue dictado por Suayambú, regenerador de la humanidad después del diluvio. Este salvador del mundo y primer rey de la India, estableció leyes teocráticas y elaboró una cronología de la creación, que él mismo había recibido de Brahma, creador del universo. El Código de Manu resume un conjunto de normas para llevar una vida justa y alcanzar la felicidad. El código traído a colación, consagraba que el juez debía ser una persona dotada de principios, inteligencia y ética.

La cultura hebrea enmarca el Talmud, que es una obra que corporiza la ley civil y canónica del pueblo judío. La Biblia y el Talmud están llenos de reglas y consejos para la buena justicia, que levanta la misión honorable de ésta hasta una consagración de verdadero privilegio en el concepto de los conciudadanos y en la perspectiva histórica. Para la interpretación y aplicación de la Ley mosaica, fueron creados en la Palestina antigua tres clases de tribunales, estos son: a) Tribunal ordinario. b) Pequeño Consejo de Ancianos de la Ciudad y, c) Gran Sanedrín o Gran Consejo de la Nación. Debe advertirse que, para la ley hebraica, en la época bíblica y aún más, en las post bíblica y talmúdica, la función del magistrado judicial gozaba de una suprema dignidad. El ejercicio de la judicatura requería una vasta cultura respecto al Pentateuco y la Mishná, así como la jurisprudencia, medicina, astronomía, geografía, ciencias físicas, matemáticas, filosofía, etcétera. En síntesis, el juez era un erudito (Goldstein, 2010).

En España en el siglo VII, el rey visigodo Recesvinto, en su código de leyes, consagró que toda autoridad que por ius imperium impartiese justicia, debía denominarse iudex que en latín significa juez. En la Constitución de Cádiz del año 1812 se plasmaron los vocablos jueces y magistrados como los designados por ley para administrar justicia. Sin embargo, cumplen funciones disímiles. 


\section{CONCEPTO Y ALCANCES DEL TÉRMINO JUEZ}

Etimológicamente, la palabra juez viene del latín iudex, iudicis, en concreto de su acusativo iudicem, que pierde como es habitual la d intervocálica, es decir, etimológicamente iudex ( juez), es quien indica, dice o decide un derecho, algo previamente establecido como norma o ley.

El juez es un funcionario del estado, que por imperio de la ley goza del "poder jurisdiccional", el cual le permite impartir justicia, al resolver controversias que son plasmadas bajo su competencia. El juez debe ser probo, diligente, impoluto, principista, ante todo un conocedor del derecho ( iura novit curia), aunque, si se trata de nuestro país, lastimosamente esto es lírico, puesto que nuestra triste realidad jurisdiccional así lo demuestra, es decir, hay jueces improvisados y de adarme sapiencia jurídica, que dictan sentencias deleznables.

La Constitución Política, así como la Ley Orgánica del Poder Judicial, prescriben como garantía de la administración de justicia, la unidad y exclusividad de la función jurisdiccional, no pudiéndose establecer jurisdicción independiente alguna, con excepción de la militar y la arbitral (Constitución, 1993). Consideramos que debería agregarse la que ejerce el Tribunal Constitucional, tratándose de los Procesos de Habeas Corpus y Amparo.

Parafraseando a José Gómez Sámano, cabe comentar que a postrimerías de la revolución francesa, que fueron los inicios de la modernidad (siglo XIX), el juez se hallaba enmarcado bajo el modelo exegético-legalista, ídem denominado bonapartista, que percibía al juez mediante una función exclusivamente mecánica: como la boca de la ley (bouche de la loi), expresión que obedece a Charles Louis de Secondat, señor de la Brède y Barón de Montesquieu. Esta clase de juez, es catalogado como un simple espectador de la historia, puesto que sólo mecánicamente podía aplicar la ley, sin poder interpretarla, ni integrarla. Este juez vivía otrora, ya que el legislador le dictaba ex-ante sus decisiones. En el siglo XX encontramos al juez "post-Nüremberg", es decir luego del juzgamiento de los culpables de la segunda guerra mundial, catalogados como los creadores del Derecho. Este juez ya es un actor de la historia, en cuanto interactúa con los otros agentes de ésta, como el poder legislativo, ejecutivo y con la misma sociedad, dialoga con ellos, convive, se interrelaciona. Finalmente, en el siglo XXI, contamos con el juez Socrático. Este juez interactúa con el pasado, con el presente e inclusive con el futuro. Este tipo de juez ya no sólo actúa en y con la historia, sino que la dirige. Acomoda a la sociedad, a través de la psicagogia, que es el arte de conducir y educar el alma y convence mediante la razón plasmada en sus sentencias, lo que considera el mejor camino para la sociedad. Sin embargo, no estarían comprendidos como jueces socráticos, todos los que componen nuestros órganos jurisdiccionales, nos referimos específicamente a los de primer, segundo y tercer nivel (Jueces de Paz Letrados, Jueces Especializados y Jueces Superiores), ya que éstos se configuran como funcionarios mecánicos del Poder Judicial, en vista de que sus resoluciones no crean jurisprudencia como fuente de derecho y no son de obligatorio cumplimiento; en cambio los del cuarto nivel, nos referimos a los jueces supremos, sí estarían contemplados como jueces socráticos, en virtud de que gozan de potestades, de las que carecen los jueces de niveles inferiores.

El filósofo y ensayista español Ortega y Gasset, quien se caracterizó por ser el exponente principal del perspectivismo, sostenía, alrededor de la tercera década del siglo XX, que del "inmenso volumen de la historia universal" se pudieran espumar tan pocos nombres inteligentes de juzgadores. Tilda al juez como un simple burócrata incapaz de modificar la realidad. A su vez lo califica como un héroe por haber elegido tan gris vocación y con un oficio triste y doloroso (Gómez, 2012)

Ortega y Gasset, en una famosa conferencia, explicó esta idea del perspectivismo con gran plasticidad escénica. Tras aludir a la escena en que Eva enseña una manzana a Adán, señalando la diversa perspectiva de los dos padres de la humanidad, se supone que con una manzana en la mano 
exclamó ante el público asistente algo parecido a esto: "La manzana que ustedes ven no es la misma que veo yo, y sin embargo se trata de la misma manzana" (Ortega, 1983).

\section{CONCEPTO Y ALCANCES DEL VOCABLO FISCAL}

Etimológicamente el vocablo fiscal proviene del término latín fiscalis, que hace referencia a lo vinculado al fisco. Es en el derecho romano donde aparece lo que podrían ser los antecesores más próximos de lo que ahora entendemos como fiscales, los "advocatus fisci". Esta figura fue creada con la misión principal de que defendieran los intereses fiscales, es decir, los impuestos, interviniendo para aumentar los bienes del fisco mediante una denominada "pena fiscal". Esta intervención se hacía aún, sin que hubiera acusación por parte del ofendido o una vez retirada ésta. Según el diccionario de la real academia española, el fiscal es una persona que representa y ejerce el ministerio público en los tribunales (Real Academia Española, 2014, definición 2).

El fiscal es un funcionario público que se encarga de representar a la sociedad en defensa de sus intereses, está a cargo de la investigación del delito, de accionar penalmente de oficio o a petición de parte, dictaminar en los procesos que se requiera y velar por la recta administración de justicia.

Los fiscales en cuanto a sus rangos, atribuciones, jerarquías, ascensos, promociones, entre otros, deben ceñirse a la Constitución Política del Perú vigente, al Decreto Legislativo $\mathrm{N}^{\circ}$. 052 que es su Ley Orgánica y a la Ley $\mathrm{N}^{\circ} 30483$, que se configura como la ley de la Carrera Fiscal.

\section{4 ¿A QUIÉNES CORRESPONDE DENOMINAR COMO MAGISTRADOS EN NUESTRO PAÍS?}

En principio, es menester conocer el origen etimológico del vocablo magistrado. En consecuencia, diremos, que deriva del término latino "magistratus", que a su vez proviene de "magister", que significa "maestro". Este último, por su parte, es el que enseña, no sólo conocimientos, sino también formas de comportamiento. Esta palabra refiere a un funcionario estatal que administra justicia en un Tribunal Supremo y/o Superior ponderando la organización jerárquica. Según la Real Academia Española magistrado significa: Miembro de la carrera judicial con categoría superior a la del juez. (Real Academia Española, 2014, definición 1).

\section{1 ¿Se deben denominar magistrados a todos los que por ius imperium imparten justicia dentro del Poder Judicial?}

La norma fundamental, al regular la exclusividad de la función jurisdiccional, consagra la expresión "magistrados judiciales", para referirse a todos los jueces en general (Constitución Política del Perú, 1993, art. 146). Asimismo, conforme a lo prescrito por el artículo 5 de la Ley Orgánica del Poder Judicial (Decreto Legislativo Nro. 767), se denomina magistrado a todos los jueces del Poder judicial, sin distinción de nivel, rango, especialidad o denominación.

Otrora, el término juez únicamente se empleaba para los Jueces de Paz Letrado y para los Jueces Especializados, puesto que a los hoy denominados Jueces Superiores, se les designaba como Vocales Superiores y a los que en la actualidad se les nombra como jueces supremos, se les proclamaba como Vocales Supremos.

En otros países del orbe, los vocablos juez y magistrado no son equivalentes.

Como norma general, la palabra magistrado designa a aquellos que imparten justicia por medio de los colegiados en los tribunales de orden superior en cada país, es decir, tribunales no ordinarios (tribunales superiores de justicia, supremos, constitucionales y otros órganos similares). En la mayoría de naciones (singularmente las occidentales), el poder judicial es independiente del poder legislativo y el ejecutivo y para que la independencia de la justicia se mantenga se crean 
instituciones con este propósito (en Italia es el Consejo Superior de la Magistratura, en Francia igual se denomina Consejo Superior de la Magistratura, en Estados Unidos la Corte Suprema Federal, en España el Consejo General del Poder Judicial y en Perú La Junta Nacional de Justicia).

La figura del magistrado no debe confundirse con lo que representa un juez ordinario, pues uno y otro tienen competencias distintas fundadas en estatutos jurídicos igualmente distintos. Como idea general, el juez es un cargo unipersonal y su actividad la ejerce en un juzgado determinado, mientras que el magistrado realiza su actividad en un tribunal.

En nuestro país, a raíz de la promulgación de la ley № 29277 denominada Ley de la Carrera Judicial, todos los que imparten justicia por ius imperium dentro de los cuatro niveles, se denominan jueces. Según mi criterio, a los de primer, segundo y tercer nivel debería denominárseles "jueces" (juez de paz letrado, juez especializado y juez superior) y a los de cuarto nivel "magistrados", en tal virtud debería modificarse los alcances y contenido del artículo 2 de la Ley Orgánica de la Academia de la Magistratura (Ley Nro. 26335), art. 5 y concordantes del D. Leg. 767 (Ley Orgánica del Poder Judicial) y el artículo 3 y concordantes de la ley N²9277 (Ley de la Carrera Judicial). La razón por la cual considero que debe efectuarse esa diferenciación, obedece a que los de cuarto nivel que conforman colegiados supremos; son los únicos que están facultados por ley para crear jurisprudencia de obligatorio cumplimiento. (Art. 22 del D. Leg. 767 y art. 400, del Código Procesal Civil, modificado por ley $N^{\circ}$ 29364). Nos referimos a las Ejecutorias Supremas (sentencias casatorias que contienen doctrina jurisprudencial) y a los Precedentes que (que nacen de los plenos casatorios), respecto a estos últimos, el único resquicio que tiene un juez para obviar la aplicación de un precedente es la técnica del "distinguishing".

\section{2 ¿Es correcto denominar magistrados, a los representantes del Ministerio Público?}

Antes de pronunciarnos al respecto, recordemos ciertos pasajes de su evolución. En el Código de Procedimientos Penales de 1940, se establecieron como etapas del proceso penal: la instrucción y el juzgamiento. Además, se precisó que los fiscales, en todos sus niveles, formaban parte del Poder Judicial. Cabe precisar que en las leyes orgánicas del Poder Judicial de 1912 y 1963, el Ministerio Público fue regulado como institución autónoma, pero formando parte del Poder Judicial, con el nombre de Ministerio Público o Ministerio Fiscal. El 28 de julio de 1979 terminó una larga etapa del desarrollo del Ministerio Público ligado al Poder Judicial (Ministerio Público [mpfn], s.m.).

Al llegar a mediados de 1979, la historia del Ministerio Público cambió radicalmente. La Constitución Política del Perú de 1979, aprobada por la Asamblea Constituyente de 1978, le atribuyó personería propia, con independencia, autonomía, organización, composición, funciones, atribuciones y prohibiciones; conforme a los artículos 250 y 251 del Capítulo XI. Desde aquella data, el Ministerio Público es una entidad autónoma íntegramente, aunque no es un Poder Constituido, como si lo es el Poder Judicial.

Posteriormente, se elaboró la Ley Orgánica del Ministerio Público, instituida en el Decreto Legislativo Nro. 052 (19 de marzo de 1981), la cual sigue vigente, aunque con las modificaciones propias de la Constitución Política de 1993 y de la ley de la Carrera Fiscal (Ley 30483).

Recapitulando, según la RAE, se entiende como magistrado al "Miembro de la carrera judicial con categoría superior a la del juez". Asimismo, y por extensión, se instaura que los jueces y magistrados tienen la potestad de juzgar y de sentenciar a los encausados.

El artículo 159 de la Constitución Política del Perú consagra las atribuciones de los fiscales como representantes del Ministerio Público, pero en ningún acápite se le faculta a juzgar y sentenciar a los encausados, puesto que esa es función exclusiva de los jueces, también denominados magistrados Como se puede apreciar, el fiscal sólo es un funcionario público que cumple con las actividades taxativas que dispone la constitución y demás leyes concordantes. En tal virtud, el único que in stricto sensu debe denominarse magistrado, es el que por imperio de la 
ley ad hoc, imparte justicia en los Tribunales Superiores o Supremos. A mayor abundamiento, ni la Constitución Política del Perú, ni la Ley Orgánica del Ministerio Público (Decreto Legislativo $\mathrm{N}^{\circ}$. 052), los denominan como magistrados con excepción del artículo 2 de la ley 26335 (Ley Orgánica de la Academia de la Magistratura e inciso 2 del artículo 6 y 7 de la ley $\mathrm{N}^{\circ} .30483$ (ley de la Carrera Fiscal), preceptos que en cuanto a su contenido no lo compartimos, porque consideramos que no se ajustan a derecho y justicia, aunque quizás sí a lo legal, puesto que no todo lo legal se ajusta a derecho y justicia, en consecuencia, recordamos el aforismo latino "Summum ius summa iniuria" (excesivo derecho, excesiva injusticia), otros dirán hecha la ley, hecha la trampa; sin embargo, pienso que es cuestión de interpretación, respecto al contenido y alcances de la ley. Cabe plantear una interrogante complementaria ¿Existe en algún lugar del Perú, una Asociación de Magistrados Fiscales?

Ergo, no existiendo argumentación doctrinaria, ni jurídica convincente, concluimos que los fiscales no son magistrados en sentido estricto.

Sugerimos que se modifique, el artículo 2 de la Ley Orgánica de la Academia de la Magistratura por el siguiente texto:

\section{Artículo 2. La Academia de la Magistratura tiene por objeto:}

a) La formación académica de los aspirantes a cargos de jueces y magistrados del Poder Judicial o representantes del Ministerio Público.

b) La capacitación académica para los ascensos de los jueces del Poder Judicial o de los representantes del Ministerio Público.

c) La actualización y perfeccionamiento de los jueces o magistrados del Poder Judicial o de los representantes del Ministerio Público.

Asimismo, deben modificarse los artículos 6 y 7 de la ley de la Carrera Fiscal (Ley $\mathrm{N}^{\circ}$. 30483), bajo el siguiente tenor:

\section{Artículo 6. Requisitos especiales para fiscal supremo}

Para ser elegido fiscal supremo se exige, además de los requisitos generales:

2. Si es representante del Ministerio Público, haber ejercido el cargo de fiscal superior titular o fiscal adjunto supremo cuando menos diez (10) años y si no lo es, haber ejercido la abogacía o desempeñada docencia universitaria en materia jurídica por quince (15) años.

\section{Artículo 7. Requisitos especiales para fiscal superior o fiscal adjunto supremo} generales:

Para ser elegido fiscal superior o fiscal adjunto supremo se exige, además de los requisitos

2. Si es representante del Ministerio Público, haber ejercido el cargo de fiscal provincial titular, fiscal adjunto superior titular, o juez especializado o mixto titular durante cinco (5) años y si no lo es, haber ejercido la abogacía o desempeñado la docencia universitaria en materia jurídica, por un periodo no menor de diez (10) años. 


\section{3 ¿Cabe denominar magistrados a los representantes de otros entes autónomos en nuestro País?}

\subsubsection{Jurado Nacional de Elecciones}

Este organismo autónomo, se encarga de administrar justicia en materia electoral y velar por el respeto y cumplimiento de la voluntad popular manifestada en los procesos electorales. Cuenta con una Ley Orgánica $\mathrm{N}^{\circ}$ 26486, la misma que regula su composición, atribuciones, entre otros aspectos. Ningún artículo de la ley en mención, emplea el término magistrado para referirse a los integrantes de este ente público.

Teniendo en cuenta la composición del Jurado Nacional de Elecciones, regulada en el artículo 10 de su Ley Orgánica, consideramos que el epígrafe de magistrado, no les es aplicable, en tal virtud, la denominación que debemos emplear es el de "Miembros del Pleno del Jurado Nacional de Elecciones".

\subsubsection{Junta Nacional de Justicia}

Es un ente autónomo que cuenta con una Ley Orgánica $\mathrm{N}^{\circ} 30916$, la misma que regula su composición, facultades y otros aspectos complementarios. Ningún artículo de la ley citada, contempla el término magistrado para referirse a los miembros integrantes de este organismo.

La Junta Nacional de Justicia, se encarga de nombrar, previo concurso público de méritos y evaluación personal, a los jueces y fiscales de todos los niveles. Asimismo, tienen la potestad de ratificar, con voto público y motivado, a los jueces y fiscales de todos los niveles cada siete (7) años. Nombrar o renovar en el cargo al jefe de la Oficina Nacional de Procesos Electorales (ONPE); Nombrar o renovar en el cargo al jefe del Registro Nacional de Identificación y Estado Civil (RENIEC).

Para nosotros los siete integrantes titulares de la Junta Nacional de Justicia, no deben denominarse magistrados, sino como su misma ley lo consagra "Miembros".

\subsubsection{Tribunal Constitucional}

El Tribunal Constitucional es el órgano supremo de interpretación y control de la constitucionalidad, es decir es el ente que se encarga de la supremacía de la Constitución (art. 51 de la Constitución Política de Perú), para lo cual ejerce el control concentrado. El Tribunal Constitucional, difiere del anterior Tribunal de Garantías Constitucionales, principalmente por sus facultades derogatorias, es decir, actualmente, si una ley es declarada inconstitucional, por medio de una resolución del TC, a partir del día siguiente de su publicación en el Diario Oficial el peruano, dicha ley queda derogada. Esto no ocurría con el Tribuna anterior, puesto que, si se encontraba inconstitucional una norma, se remitía mediante una resolución al congreso, para que este Poder Constituido lo derogase y sustituyese de ser caso por otra ley.

El primer párrafo del artículo 8 de la LOTC prescribe a la letra que: El Tribunal está integrado por siete miembros, con el título de Magistrados del Tribunal Constitucional. Cabe resaltar que muchos artículos de la ley supra mencionada enmarcan el término magistrado para referirse a los miembros del TC.

Para nosotros es correcto conforme a ley, derecho y justicia, denominar magistrados a los integrantes de este ente, puesto que, es acorde a sus jerarquías, atribuciones, naturaleza jurídica y responsabilidades. 


\section{JERARQUIZACIÓN DE LOS JUECES EN OTROS PAÍSES DEL ORBE}

\subsection{España}

Existen tres categorías en la carrera judicial: “Juez/a, Magistrado/a y Magistrado/a del Tribunal Supremo"

Para ser juez, es preciso ser licenciado en derecho y superar una oposición durísima de 350 temas memorizados. Tras esto, los elegidos tienen que pasar por la Escuela Judicial, ubicada en Barcelona, por un periodo aproximado de dos años.

De juez a magistrado se asciende en el transcurso de la vida profesional, bien porque se superen unas pruebas selectivas exclusivas para jueces, que otorgan esta condición, o por antigüedad, es decir, por tiempo en servicio activo (Gobierno de la Rioja, 2016).

Ascender a magistrado del Tribunal Supremo es algo más complejo y requiere de más tiempo.

A ellos los elige el Consejo General del Poder Judicial, que es el órgano de gobierno de los jueces, tras un concurso de méritos al que sólo se pueden presentar magistrados con quince o más años de antigüedad.

\section{¿Qué se conoce como el cuarto turno y quinto turno?}

La ley también prevé que se pueda acceder directamente a la carrera judicial como magistrado o como magistrado del Tribunal Supremo, sin pasar por las categorías inferiores. Para ello es preciso superar un concurso oposición, popularmente denominado cuarto y quinto turno. En el cuarto turno, una cuarta parte de las plazas se reservan para juristas de reconocido prestigio: profesores de derecho, abogados, etc. Mientras que el quinto turno, reservado sólo al Tribunal Supremo, consiste en ocupar una de cada cinco vacantes con juristas de reconocido prestigio.

\section{Las diferencias en la vestimenta de jueces y magistrados}

La diferencia de categorías en la escala judicial también se puede apreciar a simple vista analizando la vestimenta. Todos van togados, pero los jueces no llevan puñetas en las mangas de su toga y los magistrados sí. Además, mientras los jueces lucen una insignia plateada, todos los magistrados la llevan dorada. Esta diferencia también es palpable en las expresiones que se emplean para dirigirse a ellos; en tal sentido, para dirigirse al juez se debe decir Señoría, en cambio para referirse al magistrado se emplean las frases Ilustrísima señoría o Señoría ilustrísima.

Los jueces y magistrados constituyen un poder independiente, el Poder Judicial, tal y como proclama la Constitución Española y cada uno de ellos es depositario del citado poder. Su función básica es impartir justicia, al juzgar y haciendo ejecutar lo resuelto (Berbell y Rodriguez, 2018).

En España El Ministerio Fiscal, está representado por los fiscales en general. Todos ellos se denominan fiscales, puesto que el término magistrado, es privativo del Poder Judicial.

\subsection{En Chile}

Son jueces los de primera instancia, en cambio los que integran las Cortes de apelaciones, Tribunales unipersonales y la Corte Suprema se denominan ministros. (Poder Judicial de Chile, [PJ], s.m.).

La Fiscalía Judicial, que antes se denominaba Ministerio Público, está encabezada por el Fiscal General y se organiza en 18 fiscalías regionales y cuatro fiscalías en la región metropolitana. 
Sus integrantes se denominan fiscales, pero no magistrados, ya que esa denominación es exclusiva de los que imparten justicia.

En la nación sureña, también se denominan a los fiscales "persecutores". Es decir, persiguen la correcta aplicación de la ley, a través de sus diversas actividades. A su vez, se entiende que, la actividad persecutora del Ministerio Público, como órgano exclusivo a cargo de la dirección de la investigación penal, consiste en guiar la actividad investigativa, con igual celo tanto aquellos hechos o circunstancias que funden o agraven la responsabilidad del imputado, como también aquellos que le eximan de ella, la extingan o atenúen. El fiscal es el "custodio de la ley".

\subsection{En Colombia}

La Rama Judicial (Poder Judicial) en el país norteño, comprende a las Altas Cortes que son: La Corte Constitucional, La Corte Suprema de Justicia, El Consejo de Estado y el Consejo Superior de la Judicatura, están representados por magistrados. Los demás órganos jurisdiccionales que son: Tribunales Superiores, los Tribunales Administrativos y los Consejos Seccionales de la Judicatura, están representados por jueces, asimismo ejercen la judicatura: Los jueces del circuito, los jueces municipales en el respectivo municipio y los Jueces de pequeñas causas a nivel municipal y local y finalmente los jueces de descongestión (Rama Judicial República de Colombia [RJRC] s.f.).

La Constitución Política de Colombia de 1991, contempla en el primer párrafo de su artículo 118, el texto siguiente: El Ministerio Público será ejercido por el Procurador General de la Nación, por el Defensor del Pueblo, por los procuradores delegados y los agentes del ministerio público, ante las autoridades jurisdiccionales, por los personeros municipales y por los demás funcionarios que determine la ley. Al Ministerio Público corresponde la guarda y promoción de los derechos humanos, la protección del interés público y la vigilancia de la conducta oficial de quienes desempeñan funciones públicas. De lo expuesto se deduce que en el país vecino del norte, a los representantes del Ministerio Público no se les asigna la denominación de magistrados.

\subsection{En México}

Los integrantes de la Corte Suprema se denominan ministros, los integrantes de los tribunales de circuito colegiados, así como los que integran Tribunales unitarios se denominan magistrados y a los integrantes de los juzgados especializados se les denomina jueces (Poder Judicial de la Federación-Corte Suprema de Justicia, [PJFCSJ] s.m.).

En México, el término magistrado, se aplica solo a los integrantes de los tribunales, ergo, no es aplicable a los fiscales.

\subsection{En Brasil}

A los 11 miembros integrantes del Supremo Tribunal Federal se denominan ministros, a los integrantes de los Tribunales Regionales Federales y de los Tribunales estaduales, también se denominan ministros, y a los integrantes de los juzgados federales y estaduales jueces, sin embargo, el término magistrado es común para designar a todos los integrantes del Poder Judicial brasilero (Brasil de fato, 2018).

Cabe resaltar que, en la República Federativa del Brasil, el término magistrado, no les es aplicable a los representantes del Ministerio Público. 


\subsection{En Venezuela}

El Tribunal Supremo de Justicia, comprende seis salas y una sala Plena, 5 salas, se encuentran integradas por cinco magistrados, salvo la sala Constitucional, que se encuentra integrada por siete. La sala Plena se compone de 32 magistrados. La Corte Marcial se halla conformada por 5 magistrados; es decir, sólo estos dos entes encuadran a magistrados ya que los demás órganos de administración de justicia como son la Corte de Apelaciones y Tribunales Superiores, los Tribunales de Primera Instancia y los Juzgados de Municipio, se hallan representados por jueces (Poder Judicial de Venezuela [PJ] s.m.).

El Ministerio Público está representado por la máxima autoridad de este ente, nos referimos al Fiscal General de la República Bolivariana, luego continúan en orden descendente por jerarquía los demás fiscales. A ningún representante del Ministerio se le denomina magistrados.

\section{CONCLUSIONES}

Al concluir este breve artículo, las más relevantes conclusiones son las siguientes:

1. En nuestro país, erradamente se denomina magistrado tanto a los jueces como a los fiscales de todos los niveles, basándose sólo en interpretación gramatical de la ley.

2. Por imperio de la ley $\mathrm{N}^{\circ} 29277$, a los que imparten justicia dentro de los cuatro niveles, se les denomina jueces (Juez de Paz Letrado, Juez Especializado, Juez Superior, Juez Supremo).

3. En España a los que imparten justicia en primera instancia se les denomina jueces, a los de segunda instancia se les denomina magistrados y a los miembros del Tribunal Supremo, magistrados del Tribunal Supremo.

4. En países como Chile, México y Brasil a los magistrados de la Corte Suprema se les denomina ministros. En Chile y Brasil, a los integrantes de las Salas Superiores también se les denomina ministros, en cambio México los denomina magistrados.

5. En Brasil el término magistrado, se emplea para referirse a todos los que imparten justicia en todos los niveles, conforme lo prescribe su Constitución Federativa de 1988.

6. Consideramos que los fiscales en sentido estricto no son magistrados, puesto que carecen de atribuciones para juzgar, sentenciar a los encausados y extinguir en última instancia "el principio de presunción de inocencia".

7. Los Jueces de Paz Letrados, los Jueces Especializados y los jueces superiores, deben mantener el epígrafe de "Jueces", en cambio los Jueces Supremos, deben denominarse por ley y derecho "Magistrados".

8. En nuestro país, a los fiscales en general se les denomina magistrados, sin embargo, dicha nomenclatura obedece más a la costumbre que a la ley, puesto que si analizamos teleológica y sistemáticamente los artículos 2 de la Ley Orgánica de la Academia de la Magistratura y el inciso 2 de los artículos 6 y 7 de la ley $N^{\circ} .30483$ (Ley de la Carrera Fiscal), llegamos a la conclusión, que a los fiscales deberíamos denominarlos "Representantes del Ministerio Público", puesto que ni la Constitución, ni su propia Ley Orgánica, utilizan el término magistrado para referirse a los fiscales. (Ubi lex non distinguit, nec nos distinguere debemus) (Donde la ley no distingue, tampoco nosotros debemos hacerlo).

9. No existen concepciones doctrinarias sólidas, que avalen el empleo del término magistrado para los fiscales.

10. Deberían modificarse los contenidos y alcances del artículo 2, de la Ley Orgánica de la Academia de la Magistratura (Ley N $\mathrm{N}^{\circ}$ 26335), idem inciso 2 de los artículos 6 y 7 de la Ley $\mathrm{N}^{\circ}$. 30483 (Ley de la Carrera Fiscal); sustituyendo el término magistrado por el de representante del Ministerio Público. 
11. Es correcto conforme a ley, derecho y justicia denominar magistrados a los miembros del Tribunal Constitucional, por las razones ya expuestas con anterioridad.

12. Debe crearse una nueva Constitución Política del Perú, conforme a los mecanismos sine qua non, que comprenda exposición de motivos y se enmarquen normas diáfanas, delimitando con precisión, quiénes son los funcionarios públicos que por ius imperium tienen la facultad de ser denominados magistrados.

\section{REFERENCIA}

Goldstein. M. (2010) El Derecho Hebreo a través de la Biblia y el Talmud. Recuperado de: http://www.raoulwallenberg.net/wp-content/files_mf/6741.pdf

Ortega, J. (1983). El hombre y la gente, en Obras Completas 7, Madrid, Alianza Editorial.

Constitución Política del Perú. Diario Oficial “El Peruano”, 30 de diciembre de 1993.

Gómez Sámano, José Sebastián. (2012). La motivación Judicial. “Non ratione imperii, sed rationis imperio", en Principios de la Ética Judicial Iberoamericana, México, Suprema Corte de Justicia de la Nación/Comisión Iberoamericana de Ética Judicial.

Real Academia Española. (2014). Diccionario de la Lengua Española ( 23.a ed.).

Ministerio Público. https://www.mpfn.gob.pe/historia/

Gobierno de la Rioja. https://www.larioja.org/justicia/es/estructura-judicial-espana

Berbell, C. y Rodríguez, Y. (2018). ¿Cuál es la diferencia entre juez y magistrado en España? Recuperado de: https://confilegal.com/20180808-la-diferencia-juez-magistrado-espana/

Poder judicial de Chile. http://www.poderjudicialtv.cl/programas/institucionales-poderjudicial/conozca-la-estructura-del-poder-judicial-de-chile/

Rama Judicial de la República de Colombia. https://www.ramajudicial.gov.co/web/ley-detransparencia-y-del-derecho-de-acceso-a-la-informacion-publica-nacional/estructura-organica.

Poder Judicial de la Federación-Corte Suprema de Justicia. https://www.scjn.gob.mx/sites/default/files/material_didactico/201611/EL\%20PJF\%20AL\%20A L\%20ALCANCE_0.pdf

Brasil de Fato. ¿Cómo se estructura el Poder Judicial en Brasil?. https://www.brasildefato.com.br/2018/01/19/como-se-estructura-el-poder-judicial-en-brasil

Poder Judicial en Venezuela. https://tiempodepolitica.com/cvenezuela/poder-judicial-envenezuela/ 